\title{
Una causa infrecuente de dolor de cuello Síndrome de la apófisis odontoides coronada
}

\author{
An infrequent cause of neck pain \\ Crowned dens syndrome
}

\author{
Jonathan Franco, Alba Robles, Alexandra Banguero, Ángel Charte \\ - Barcelona (España)
}

\section{Resumen}

En la práctica clínica habitual existe un crecimiento en la demanda asistencial de servicios de urgencias. El dolor cervical es una patología muy frecuente que compete a diversos profesionales sanitarios. El síndrome de apófisis odontoides coronada, es una patología muy poco frecuente, que hace parte del espectro de las enfermedades por microcristales de pirofosfato cálcico, ocasionando una calcificación de ligamentos del proceso de odontoides cervical, llevando a una clínica de cervicalgia, fiebre y rigidez de nuca. Esta patología entra en el diagnóstico diferencial con patologías potencialmente graves. En muchas ocasiones lleva a procedimientos y gastos farmacológicos innecesarios, principalmente por el desconocimiento que la transforma en una patología infradiagnosticada. (Acta Med Colomb 2018; 43: 230-232).

Palabras clave: síndrome de la apófisis odontoides coronada, dolor de cuello, pseudogota.

\begin{abstract}
In the usual clinical practice there is a growth in the demand for emergency services. Cervical pain is a very common pathology that concerns various health professionals. The crowned den syndrome is a very rare pathology, which is part of the spectrum of microcrystalline diseases of calcium pyrophosphate, causing a calcification of ligaments of the cervical odontoid process, leading to clinical signs of neck pain, fever and neck stiffness. This pathology enters into the differential diagnosis with potentially serious pathologies. In many cases it leads to unnecessary pharmacological procedures and expenses, mainly due to the ignorance that turns it into an infra diagnosed pathology. (Acta Med Colomb 2018; 43: 230-232).
\end{abstract}

Keywords: syndrome of the crowned odontoid process, neck pain, pseudogout.
Dres. Jonathan Franco, Alba Robles, Ángel Charte: Departamento de Medicina Interna; Dra. Alexandra Banguero: Departamento de Radiología. Hospital Universitario Quirón-Dexeus. Barcelona (España).

Correspondencia: Dr. Jonathan Franco. Barcelona (España).

E-Mail: Jonathan.franco@quironsalud.es Recibido: 18/X/2017 Aceptado: 23/X/2018

\section{Introducción}

Las enfermedades por depósito de microcristales (hidroxiapatita o dihidrato de pirofosfato cálcico) son relativamente frecuentes en la población, principalmente en mayores de 60 años. Generalmente se asocian episodios de artritis aguda mono u oligoarticular, acuñado con el nombre de "pseudogota". En algunas ocasiones asocian manifestaciones sistémicas como fiebre, escalofríos y mal estado general (1). El síndrome de la apófisis odontoides coronada (SAOC) es una entidad clínicoradiológica poco frecuente, inicialmente reportada en 1985 que engloba unas manifestaciones "atípicas" de la enfermedad por microcristales (2).

\section{Caso clínico}

Se presenta un caso en un paciente de 74 años, se trata de un hombre sin antecedentes patológicos, que consultó a urgencias por fiebre de 48 horas de evolución, escalofríos, cervicalgia de predominio occipital y mal estado general. La temperatura fue de $38.2^{\circ} \mathrm{C}$, presión arterial de $132 / 81 \mathrm{~mm}$ $\mathrm{Hg}$ y frecuencia cardiaca de 105 latidos por minuto. En la exploración física, la auscultación cardiaca y pulmonar fue normal, sin alteraciones en la piel y mucosas. A nivel neurológico tenia rigidez de nuca, signo de Kernig y Brudzinsky positivos, con Glasgow 15 y sin alteraciones de pares craneales. En la analítica presentó hemograma y bioquímica sin alteraciones, destacando una proteína C reactiva de $115 \mathrm{mg} /$ $\mathrm{dL}$ y procalcitonina $<0.05 \mathrm{mg} / \mathrm{dL}$. Con la sospecha clínica de meningitis se realizó punción lumbar obteniendo líquido céfalorraquídeo (LCR) claro con 1-2 leucocitos por campo, glucosa y proteínas normales. La tinción de gram fue negativa. Se realizó cultivo del LCR y hemocultivos. Debido al deterioro clínico y la alta sospecha clínica de meningitis, se decidió iniciar cobertura antibiótica empírica y analgesia. 
Ingresa a planta de medicina interna, se realizó una tomografía axial computarizada (TAC) de cráneo, con un reporte inicial que descartaba abscesos ni alteraciones agudas. Buena evolución clínica a las 48 horas, siendo cultivos del LCR y hemocultivos negativos. Se decide disminuir pauta de analgesia (ibuprofeno). Al cuarto día de ingreso reaparece la cervicalgia y fiebre, asociando artritis de rodilla izquierda. Realizamos artrocentesis detectando líquido de características inflamatorias con gram y cultivo negativos, pero positivos en la luz polarizada para pirofosfato cálcico. Con la evolución clínica, descartamos etiología infecciosa y planteamos como posible causa una "pseudogota" con debut en forma de SAOC. Revisamos el TAC de cráneo, con énfasis en columna cervical C1-2, y comprobamos la existencia de un halo de calcificación alrededor de la odontoides (Figura 1). Descartamos causas secundarias como hiperparatiroidismo y hemocromatosis. Iniciamos manejo con prednisona a $0.5 \mathrm{mg} / \mathrm{Kg} /$ día y colchicina $0.5 \mathrm{mg} /$ día . Presentó mejoría precoz de los síntomas, por lo cual fue dado de alta al domicilio. Durante su seguimiento por consultas externas, se retira la prednisona con pauta descendente, tras tres semanas de iniciada, y se continua dosis de colchicina, manteniéndose asintomático hasta seis meses después.

\section{Discusión}

El SAOC es una patología poco frecuente, debido a depósitos de hidroxiapatita o dehidrato de pirofosfato cálcico en la columna cervical. Existen pocos casos reportados en la actualidad.

No se conoce con exactitud la fisiopatología, parece ser debida al acúmulo de condrocitos en las estructuras fibro cartilaginosas como menisco de la rodilla, que pueden encontrarse en el ligamento transverso que rodea el proceso odontoides. Otra teoría es la transformación de los fibroblastos en la columna cervical a condrocitos produciendo calcificación (2).

Como en nuestro caso, predomina en pacientes de mayor edad, principalmente $\geq 70$ años, con la misma frecuencia en hombres y mujeres. La clásica triada clínica se caracteriza por cervicalgia (100\%), rigidez de nuca $(98 \%)$ y fiebre $(80.4 \%)$. Estos síntomas típicos podrían confundirse frecuentemente con meningitis, absceso epidural, polimialgia reumática, artritis de células gigantes, artritis reumatoide, espondilitis cervical o tumores de la columna cervical. Es importante tener en cuenta estos diagnósticos diferenciales, ya que genera, en la mayor parte de los casos, que se se realicen procedimientos innecesarios e invasivos (punción lumbar, biopsia de arteria temporal), así mismo, la administración de tratamientos inapropiados y la prolongación de la estancia hospitalaria (3).

El diagnóstico, requiere la sospecha clínica e imágenes diagnósticas. Radiológicamente, el Gold estándar para el diagnóstico de SAOC es: TAC cervical con énfasis en C1-2 (4). En la TAC se ve calcificación del ligamento cruciforme, rodeando el proceso odontoides, además nos ayuda a descartar otras causas de dolor cervical como pueden ser las fracturas y los tumores primarios o metastásicos. Como precaución, si el TAC se realiza mucho tiempo de iniciado los síntomas, se reabsorberán los cristales y es posible no ver la calcificación, por lo tanto, lo ideal es tal y como nuestro caso, realizarla precozmente (Figura 1). Radiografías simples de rodillas o muñecas, a pesar de la ausencia de síntomas

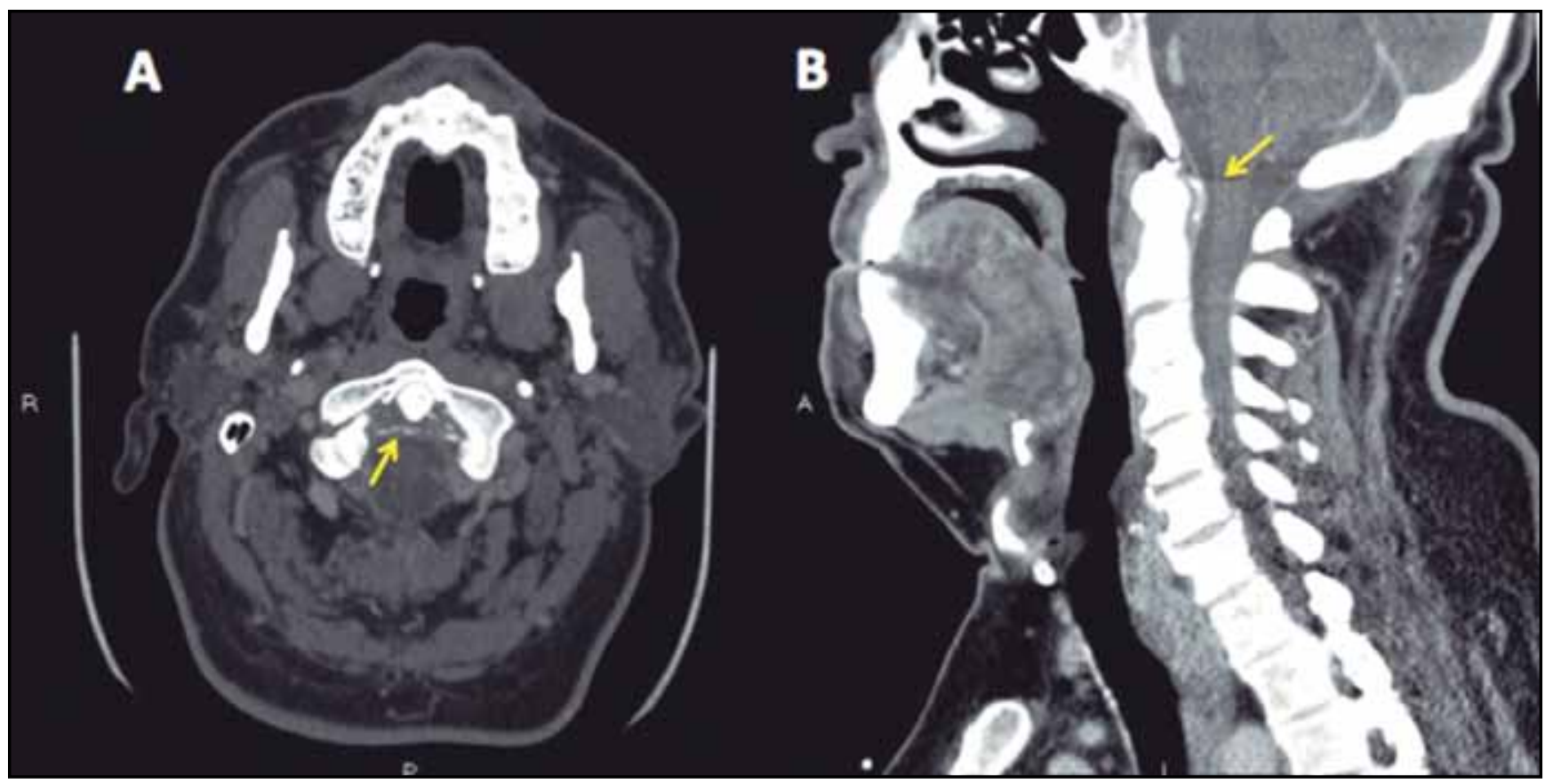

Figura 1. Tomografía axial computarizada centrada en C1-2. A: Ventana de hueso axial: Calcificación de los ligamentos periodontales, particularmente la banda transversal y alar del ligamento cruciforme. B: ventana del hueso sagital. 
específicos, podría ser de utilidad por la alta asociación entre afectación poliarticular en el grupo de pacientes con SAOC.

En el estudio del líquido articular se pueden encontrar cristales romboidales con birrefringencia positiva (patognomónicos de la enfermedad por depósito de pirofosfato cálcico), los cuales confirmarían el diagnostico de certeza (5). Es frecuente ver respuesta inflamatoria sistémica, con elevación de la proteína c reactiva; sin embargo, un dato que podría ayudarnos a diferenciar esta respuesta inflamatoria, en el diagnóstico diferencial, es medir procalcitonina, la cual es un marcador con elevada sensibilidad y especificidad para infección bacteriana, siendo negativa en esta patología.

No existe un consenso en el tratamiento del SAOC. Como alternativas terapéuticas, está descrito el uso de corticoides y/o antiinflamatorios no esteroideos (AINES). Los AINES han demostrado su utilidad, ya que permiten la remisión de la clínica en cuestión de días a semanas (6). Otro medicamento, la colchicina oral a una dosis de 0.5-1 mg/día se emplea en aquellos pacientes sin disfunción renal y/o hepática, además presenta eficacia como profilaxis para disminuir la frecuencia de episodios agudos. Como tratamientos de alternativos, en caso de ausencia de respuesta, está la hidroxicloroquina y metotrexate, este último con acción tanto inmunosupresora como antiinflamatoria (7).

Nuestro paciente, recibió prednisona a dosis moderadas $(0.5 \mathrm{mg} / \mathrm{kg} / \mathrm{día})$, en pauta descendente durante tres semanas. La fiebre, cervicalgia y rigidez de nuca desaparecieron entre el día tres y cinco de tratamiento, así mismo se normalizaron los niveles de proteína c reactiva. Desde el inicio se administro colchicina $(0.5 \mathrm{mg} /$ día), continuando hasta seis meses como profiláctico. Se realizó también rehabilitación física. El paciente fue controlado seis meses tras el alta hospitalaria, encontrándose asintomático.

El SAOC es una patología asociada a las enfermedades por depósito de microcristales, con una prevalencia baja, probablemente por infradiagnóstico, y los profesionales que atiendan a estos pacientes deberán estar alerta para su correcto diagnóstico, evitando procedimientos y tratamientos innecesarios, en un escenario tan frecuente como es el dolor cervical.

\section{Referencias}

1. Rosenthal AK, Ryan LM. Calcium Pyrophosphate Deposition Disease. N Engl J Med 2016;374:2575-84.

2. Dirheimer Y, Bensimon C, Christmann D, Wackenheim C. Syndesmo-odontoid joint and calcium pyrophosphate dihydrate deposition disease (CPPD). Neuroradiology 1983;25:319-21.

3. Koda R, Tsuchida Y, Yoshizawa K, Suzuki K, Kasai A, Takeda T, et al. Crowned Dens Syndrome as an Initial manifestation of Crystalline Deposition Disease. Intern Med 2015;54:2405-08.

4. Takahashi T, Tamura M, Takasu T, Kamei S. Clinical and quantitative analysis of patient with crowned dens síndrome. J Neurol Sci. 2017;376:52-59.

5. Oka A, Okazaki K, Takeno A, Kumanomido S, Kusunoki R, Sato S, et al. Crowned dens síndrome: Report of three cases and review of the literatura. $J$ Emerg Med. 2015;49:e9-e13.

6. Rosales-Alexander JL, Balsalobre Aznar J, Magro-Checa C. Calcium pyrophosphate crystal deposition disease: diagnosis and treatment. Open Access Rheumatol. 2014;6:39-47

7. Shikino K, Ota T, Ikusaka M. Crowned Dens Syndrome. Am J Med. 2017;130:e111-e112. 